\title{
Mathematical simulation of heat exchanger working conditions
}

\author{
Stanislav Gavlas ${ }^{1}$, Peter Ďrčanský, ${ }^{2, a}$, Richard Lenhard ${ }^{1}$ and Jozef Jandačka ${ }^{1}$ \\ ${ }^{I}$ University of Žilina, Faculty of mechanical engineering, Department of energy technology, Univerzitna 1, 01026 Žilina, \\ Slovak Republic \\ ${ }^{2}$ University of Žilina, Research centre of University of Žilina, Univerzitna 1, 01026 Žilina, Slovak Republic
}

\begin{abstract}
One of the When designing a new heat exchanger it is necessary to consider all the conditions imposed on the exchanger and its desired properties. Most often the investigation of heat transfer is to find heat surface. When applying exchanger for proposed hot air engine, it will be a counter-flow heat exchanger of gas gas type. Gas, which transfers the heat will be exhaust gas from the combustion of biomass. An important step in the design and verification is to analyze exchanger designed using numerical methods, the verification of the correctness of design and verification of boundary conditions which include temperatures, flow rates and pressure drops. Due to the fact that the heat transfer in the heat exchanger is a three-dimensional plot and timeindependent, the system is described by partial differential equations that need to be solved by numerical methods.
\end{abstract}

\section{Unconventional mikrocogeneration unit}

Among many possibilities of generating electricity from fossil fuels through combustion with internal combustion engines, gas turbines, steam power plants and other facilities are also another machines with external combustion. Except for units with internal combustion engines these are large devices which require intensive operation and maintenance. Overall efficiency of such devices increases with the use of cogeneration technologies of energy - heat removal from flue gases and cooling liquids. Another problem is the dependence of such devices on fossil fuels, as fuel for combustion turbines is most used natural gas or kerosene and fuel for heating plants is used coal. A possible alternative to conventional internal combustion engines are hot-air engines, which are Stirling and Ericsson engine. Development of hot air engines is still in the shadow of the classic internal combustion engines, fuel cells, new electrical batteries and advanced photovoltaic panels. One of the reasons why piston engines with external heat input is currently not promoted significantly are problems with the solution of sealing and lubrication at high temperatures and high operating pressures. Basic sketch of the units is shown in Fig. No. 1 In the case of Stirling engine is immediately obvious double function of regenerator. Regenerator $(\mathrm{R})$ functions as heater or cooler and energy storage, while at Ericsson engine radiator and heater are separate heat exchangers and efficiency of the machine is not as significantly affected by the volume of the regenerator as by the Stirling engine. [1] In Ericsson cycle air is compressed in the compression cylinder, after compression flows through the heat exchanger where the heat receives at fixed pressure heat energy. Subsequently is led to the expansion cylinder, which expands adiabatically and is acting work. [2] Part of this work will be used to drive the compressor and part is used as part of the mechanical work to drive an electric generator.

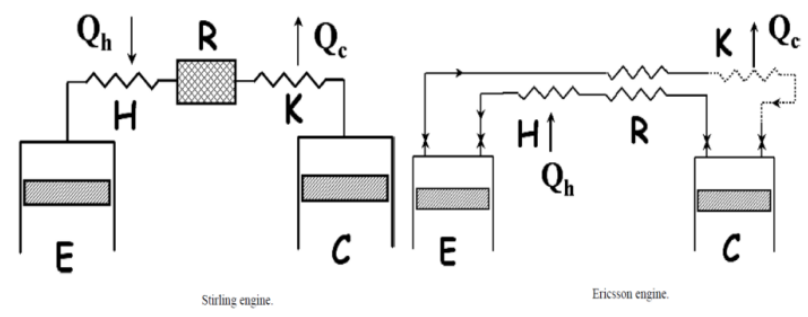

Figure 1. Scheme of Stirling and Ericsson hot air engine. [3]

The source of heat for the system with hot air engine is furnace designed to burn biomass, whether in the form of wood logs or pellets. Transport of energy from the combustion of biomass into working medium of Ericsson or Stirling engine, ensures heat exchanger direct connected to that furnace. The heat exchanger is therefore an important part of the hot air engine that serves to transformation of energy from biomass to mechanical work and then to electricity.

\footnotetext{
${ }^{\mathrm{a}}$ Corresponding author: peter.durcansky@fstroj.uniza.sk
} 


\section{Proposal of heat exchanger}

When designing a new exchanger it is necessary to consider all the conditions imposed on the exchanger and its desired properties. Most often the investigation of the exchanger it led to find needed heat exchange surface. From it are then derived all other parameters of exchanger - external dimensions, connecting dimensions, such as flanges, pipe connections dimensions, mounting flanges, brackets dimensions and retaining structures. If there are other circumstances, such as the need to place the exchanger into some defined volume or place heat exchanger in specified machine then the computation is determined by calculating the best exchanger design to the most real properties of a particular exchanger close to desired theoretical values. When designing exchanger for hot air engine we have decided that it will be a counterflow heat exchanger type gas - gas.[4] Gas which transfers the heat will be exhaust gases from the combustion of biomass in furnace and gas, which receives heat from combustion will be either dry air or one of the inert gases such as nitrogen. The main requirements for this exchanger will therefore be slightly different. One of the important conditions will be strength even at high temperatures of combustion gases. From many available design solutions are best suitable tube exchangers, [5]. Therefore we have proceeded to draft heat exchanger proposal for this application. Our preferred arrangement is shown in Figure 2, we have used tubes with meandering shape, where the shape of tubes is adapted to the built volume of. The tubes have a common collector at inlet and outlet.

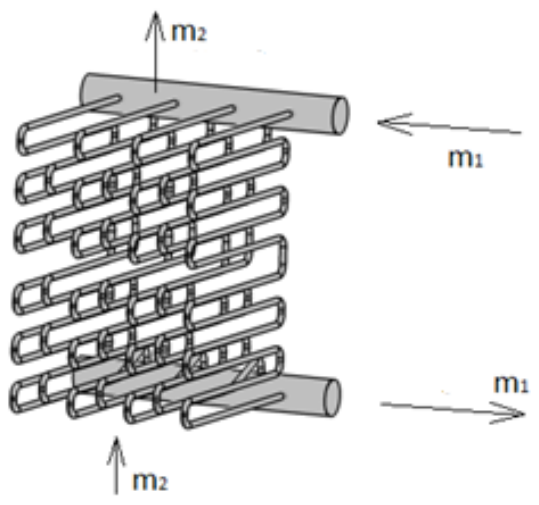

Figure 2. Schematic illustration of the inputs and outputs of proposed heat exchanger.

The air enters the collector tube on the top and heated flows from the lower header. In space between tubes air flows vertically. Exchanger is designed as a crosscountercurrent, which will bring savings in the built volume, and this arrangement also allows us to work with smaller temperature gradient between both mediums. After a preliminary determination of dimensions we have proceeded to the calculation of the heat exchanger using numerical methods.

\section{Calculation of parameters of the heat exchanger using numerical methods}

As first step we have set the working conditions of the combined heat power plant. Our apllication with hot air engine sets wide range of specifications, not only on the heat exchanger, but also on the whole system. We are assuming the temperature of the working fluid after expansion in range from $240^{\circ} \mathrm{C}$ to $320^{\circ} \mathrm{C}$ [4]. For each working fluid, the dry air in the tubes and the exhaust gases outside the tubes, we have set the characteristically temperatures and physical properties. For the formula we use literature [6] and [7]. Main temperature for heat transfer through pipes in bundle is:

$$
\Delta T_{l n}=\frac{\Delta T_{M A X}-\Delta T_{M I N}}{\ln \frac{\Delta T_{M A X}}{\Delta T_{M I N}}}
$$

The difference if the tubes are straight or staggered, or partly staggered, is characterized with dimensionless constants.

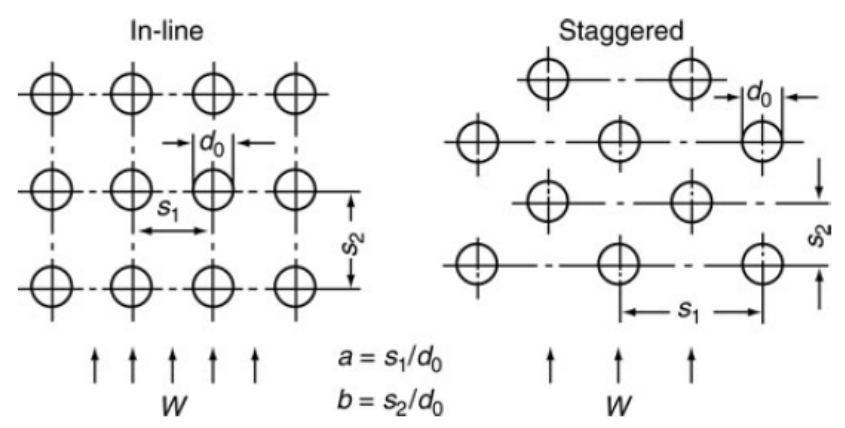

Figure 3. Lateral and longitudinal spacing in tube bundles.

If the tube bundle has horizontal spacing " $\mathrm{s}_{1}$ " and vertical spacing " $\mathrm{s}_{2}$ ", we can characterize the bundle with these constants:

$$
\begin{gathered}
a=\frac{s_{1}}{d_{0}} \\
b=\frac{s_{2}}{d_{0}} \\
\psi=1-\frac{\pi}{4 . a}
\end{gathered}
$$

Also we can define the streamed length "l", that can be expressed as length of flow path transverse over a single tube [7] :

$$
l=\frac{\pi}{2} \cdot d_{o}
$$


Another difference can we see in the non-dimensional criteria. Reynolds number is characterizing the flowing medium and the type of flow. It depends on flow velocity and also on the geometry. For heat transfer through tubes in bundle we can use following Reynolds number criteria:

$$
R e=\frac{w \cdot l}{\psi \cdot v}
$$

Nusselt number is characterizing the heat transfer. If the turbulence in the inflowing medium is low, deviations in the Nusselt number may occur. The average Nusselt number in a cross-flow over a bundle of smooth tubes can be calculated from that in a cross-flow over a single tube. For our purpose we have used the criteria equation according to [7], [8]. The heat transfer is described by the 2 parts of flow, the turbulent part and the laminar part of the flow near the walls:

$$
\begin{gathered}
N u_{l, l a m}=0,664 \cdot \sqrt{\operatorname{Re} \psi, l} \cdot \sqrt[3]{P r} \\
N u_{l, t u r b .}=\frac{0,037 \cdot R e_{\psi, l}^{0,8} \cdot \operatorname{Pr}}{1+2,443 \cdot \operatorname{Re} e_{\psi, l}^{-0,1} \cdot\left(\operatorname{Pr}^{2 / 3-1}\right)}
\end{gathered}
$$

Turbulent flow in pipe sets in at $\operatorname{Re}>10^{4}$. In the transition region of Reynolds number from 2300 to $10^{4}$ the type of flow is also influenced by the nature of inlet stream and the form of pipe inlet. Tube bundles with inline tubes behave more like parallel channels, which are formed by the tube rows. An expected increase in heat transfer coefficient due to the turbulence enhancement caused by the tube rows does not occur. [7]

Our aplication for hot air engine will use as primary heat exchanger tube heat exchanger with staggered tubes. For this type of heat transfer through tube bundle we can define, according to [7], the average Nusselt number for bundle:

$$
N u_{0, \text { bundle }}=\frac{1+(n-1) \cdot f a}{n} \cdot N u_{l, 0}
$$

where:

$$
\begin{gathered}
f_{a, \text { stag }}=1+\frac{2}{3 b} \\
N u_{l, 0}=0,3+\sqrt{N u_{l, l a m+}^{2} N u_{l, t u r b}^{2}}
\end{gathered}
$$

Then followed the estimation of overall coefficient of heat transfer that is depending on the Nusselt number.

$$
\alpha=\frac{N u_{\text {bundle }} \cdot \lambda_{T M}}{l}
$$

The overall coefficient of heat transfer was set for both mediums and for wall is known the coefficient of thermal conductivity. When we know both sides of equation, we can compare them together and estimate the overall heat transfer coefficient and the needed heat transfer surface.

After this we have proceed to creation of 3D model of the exchanger. The model was in first step created with wall thickness of tubes and inlet tubes.

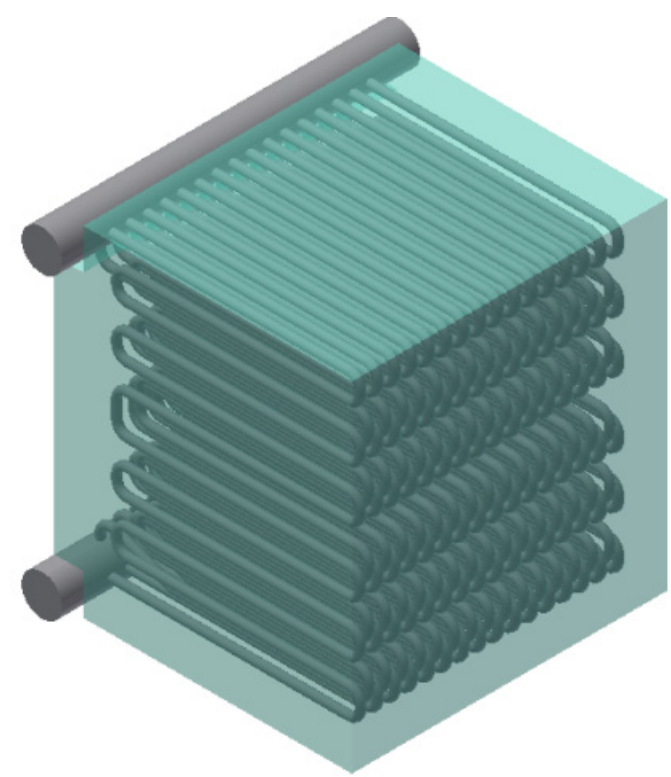

Figure 4. 3D model of proposed heat exchanger.

But this solution sets major requirements on computing hardware, so we have decided to create a simplified model with tubes as full material and only set the right material constants for the surfaces. The model has substituted all the construction elements by simple geometrical features. This means, that the whole exchanger was modeled as one volume with tubes as full material. The tubes have multiple collectors at inlet and outflow and no construction tolerances were reflected. The exteriour of the heat exchanger was created by cutting out material from volume and the model was solved with polyhedral mesh and K- $\varepsilon$ model. The flow was predicted as turbulent with $15 \%$ intensity. In the Fig. 4 we can see velocity fields and in Fig. 5 is shown the temperature field in section view. Monitored were inlet and output pipes temperature, that is depending on the overall heat transfer. The current model has confirmed the mathematical model and also accuracy of chosen geometry and has confirmed proposed temperatures at pipe outlet.

The result of CFD simulation is a mathematical model that describes the state variables and changes in these variables in the heat exchanger. We are able to observe state changes in whole exchanger volume, or in any part or section.

The first observed variable was heat exchanger performance, which came to $12.8 \mathrm{~kW}$ and from numerical model has only $6 \%$ deviation. From the CFD simulation was then shown the profile of flow velocity, in Fig. 5 and the temperature profile, shown in Fig. 6 in a sectional plane. 

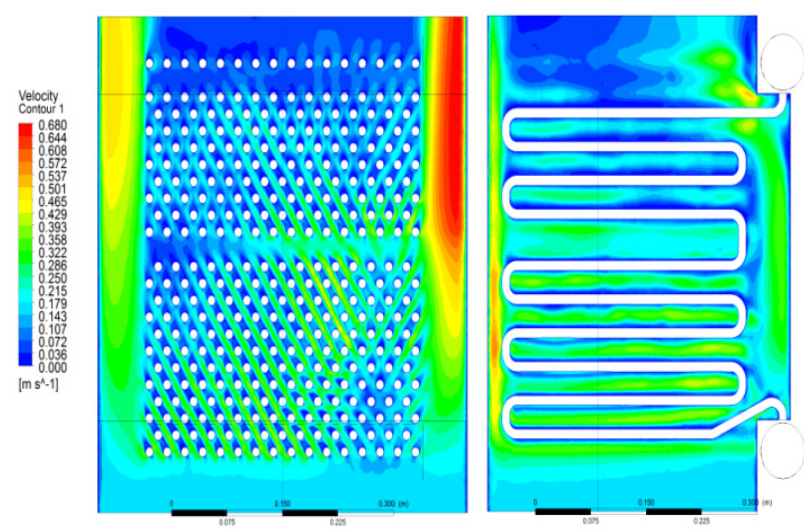

Figure 5. Velocity fields in proposed heat exchanger.

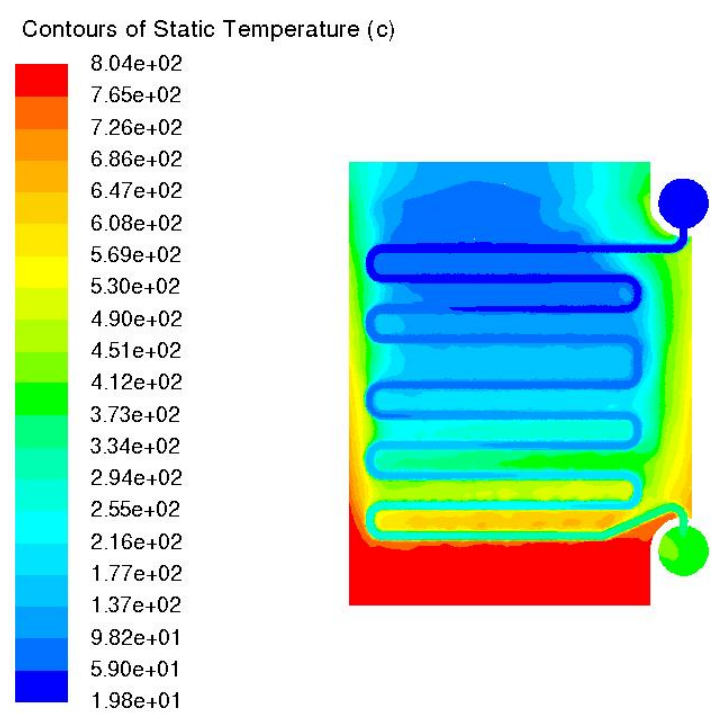

Figure 6. Temperature fields in proposed heat exchanger.

\section{Conclusion}

Heat exchanger design for hot air engine sets wide range of specifications. As first step was defined the working conditions of whole unit and the required power and temperatures for each part of this device. The basic dimensions of heat exchanger were set using criterion formula. With this calculation was verified the inlet and outlet temperatures of the heat exchanger. Then followed the calculation using Ansys Fluent. Next step was to complete the construction documentation and finish all design fundamentals, so the construction and real measurements can follow.

\section{Acknowledgments}

This work is supported by "Výskum nových spôsobov premeny tepla z OZE na elektrickú energiu využitím nových progresívnych cyklov" ITMS 26220220117. $(50 \%)$.

This work is supported by the European Regional Development Fund and the State budget with project
"Research Center of University of Zilina" ITMS $26220220183(50 \%)$

\section{References}

[1] Creyx M., "Energetic optimization of the performances of a hot air engine for micro-CHP systems working with a Joule or an Ericsson cycle" in Elsevier, France, 2012.

[2] Kalčík J., Sýkora K.: Technická termodynamika, Praha: Academia Praha, 1973, pp. $301-318$.

[3] Bonnet S., Alaphilippe M., Stouffs P, Energy, exergy and cost analysis of a micro-cogeneration system based on an Ericsson engine in Elsevier, France, (2003)

[4] Durčanský P., Jandačka J., Kapjor A., Papučík Š, "Návrh výmenníka tepla pre Ericsson-Braytonov motor" in SKMTaT 2013 edited by K. Kaduchova, Tatranská Lomnica, Slovakia, 2013, pp. 21-25

[5] Nemec, P., Hužvár, J. Proposal of heat exchanger in micro cogeneration unit, configuration with biomass combustion, Materials science and technology,Žilina, Slovakia, 2011

[6] Stehlík, P., a kol., Tepelné pochody, výpočet výmenníku tepla, Brno: VUT Brno, 1991, pp. 40-56.

[7] Verein Deutscher Ingenieure, VDI heat atlas, Berlin Heidelberg: Springer-Verlag, 2010, pp. 720-740.

[8] R. Lenhard, M. Malcho, "Numerical simulation device for the transport of geothermal heat with forced circulation of media" in Mathematical and Computer Modelling, 2013, vol. 57, iss. 1-2, p. 111-125. 